\title{
The Role of Preliminary Mechanical Activation in the Process of Obtaining Powder-Like Ferrosilicium from Metallurgical Slags
}

\author{
Vilena Hakob Martirosyan, Marine Eduard Sasuntsyan \\ Department of Chemical Technologies and Environmental Engineering, National Polytechnic University of \\ Armenia (NPUA), Yerevan, Armenia \\ Email:v.a.martirosyan@mail.ru,msasuntsyan@mail.ru
}

Received 4 January 2016; accepted 4 April 2016; published 7 April 2016

Copyright (C) 2016 by authors and Scientific Research Publishing Inc.

This work is licensed under the Creative Commons Attribution International License (CC BY). http://creativecommons.org/licenses/by/4.0/

(c) $\underset{\mathrm{EY}}{\mathrm{EP}}$ Open Access

\section{Abstract}

Powder iron monosilicide with certain structure exhibits magnetic properties and can be used as an alloying additive in the production of electrical steels and silicon alloys with special physical and chemical properties. From this point of view, development of the energy-saving technology for receiving such a valuable alloying agent with the disposal of secondary waste is an urgent task. For this purpose, the method of joint aluminothermic reduction of preliminary mechanically activated metallurgical waste is offered. Recently, a method for combining the self-propagating high-temperature synthesis and preliminary mechanical activation for obtaining metal powders with certain phase composition and structure is considered as one of the efficient ones. As the initial materials for obtaining iron monosilicide, the waste (or converter) slags of the Alaverdi coppersmelting plant and molybdenum slags of the Yerevan Pure Iron Plant are used. Besides the mentioned slags, $\mathrm{NaNO}_{3}$ and $\mathrm{CaO}$ are added. Properties and structure of the received silicide depend on the contents, quantity of components, and the mass relation of two wastes in the burden. Therefore, the processes of structure formation of the iron monosilicide received from metallurgical waste are investigated. Studies have shown that the best results are obtained in case of waste and molybdenum slag relation of $4: 1$, when the 60 -minute grinding in the vibromill leads to a significant increase in the mechanical activation of the burden. At this relation of $\mathrm{FeO}$ and $\mathrm{SiO}_{2}$, a condition is created for receiving iron monosilicide showing magnetic properties. On the whole, those transformations lead to a decrease in the reaction activation power of the interacting substances, an increase of the reactivity capacities, as well as to a new original course of reactions and new modified materials. 


\section{Keywords}

\section{Mechanochemical Activation, Copper Concentrate, Silicon Concentrate, Slag, Grinding, Vibromill, Aluminothermic Reduction}

\section{Introduction}

Recently, a method for combining the self-propagating high-temperature synthesis (SHS) and preliminary mechanical activation (MA) for obtaining metal powders with certain phase composition and structure is considered as one of the efficient ones. The mechanoactivated self-propagating high-temperature synthesis (MASHS) allows to obtain materials and alloys with unique properties by using simple equipment and spending little power at the expense of the heat generated from the reduction reaction.

The purpose of the work is to study the process of preliminary mechanical activation of the burden required for obtaining powder ferrosilicium with certain properties by its fine crashing in the vibromill.

In the grinding process, the impact of the external mechanical forces causes different relaxations and deformations of the stress field, which in their turn are connected with the inter-particle changes and defects occurring in the crystalline lattice, as a result of which the temperature of all the structural transformations, including the amorphisation temperature, decreases. All these structural deviations strongly influence the reactivity capacities of the materials. On the whole, those transformations lead to a decrease in the reaction activation power of the interacting substances, an increase of the reactivity capacities, as well as to a new original course of reactions and new modified materials [1] [2].

As the initial materials for obtaining ferrosilicium, the waste (or converter) slags of the Alaverdi coppersmelting plant rich in iron $(\sim 50 \% \mathrm{FeO})$ and molybdenum slags rich in silicon $\left(\sim 80 \% \mathrm{SiO}_{2}\right)$ of the Yerevan Pure Iron Plant are used. Besides the mentioned slags, $\mathrm{NaNO}_{3}$ is added to increase the thermal capacitites of the burden, and $\mathrm{CaO}$ for slag generation. By the high-temperature (aluminothermal) reduction of the burden prepared with the mentioned components, ferrosilicium is obtained with certain phase composition and structure. For that purpose, complex physico-chemical investigations of the burden have been carried out (microscopic, X-ray phase, grinding degree and surface morphology) to find out the opportunities of increasing its reactivity due to preliminary mechanical activation.

\section{The Method of Investigation}

For investigation, the converter (sample No. 1) and waste (sample No. 2) of the Alaverdi copper-smelting plant and the molybdenum (sample No. 3) slags of the Yerevan Pure Iron Plant are taken. The study of components in the slags calculated by corresponding oxides is implemented on the certified X-ray fluorescent spectrometer ED 2000 produced by the "Oxford Instruments Analytical" Company (Great Britain) [3] [4].

The morphology of the cover surface was studied on the high-resolution electronic scanning microscope Mira of Tescan Company (Czech Republic) using a microroentgeno spectral analyzer INCA Energy 350 [4] [5]. The research wacarried out according to the X-ray characteristic line surfaces. While determining, a distribution map was shown on the computer display. The element concentration was determined by the intensity of the colour. The greater was the darkening degree of the laser, the greater the element concentration was. As a surface active material, the sodium hexametaphosphate was used [5] [6].

The experiments of mechanochemical activation have been implemented in the vibromill of the type M-30 [7] [8] [9]. The mill's volume was $600 \mathrm{~cm}^{3}$, number of rotations $-425 \mathrm{rot} / \mathrm{min}$, and power- $2.8 \mathrm{kWt}$. The mill consists of two drums placed opposite each other. The first drum is filled with $50 \mathrm{~g}$ of dry slag, while the second one with the wet slag of the same weight. The activation duration was 15, 30, 45, and 60 minutes. However, the diagrams mainly indicated 60 minutes, so that the phase changes of the minerals depending on the grinding could be seen more clearly. To obtain comparable data, the grinding experiments have been carried out under equal conditions.

\section{Experimental Part}

The mechanochemical activation of slags with the burden components takes part. To carry out the mechano- 
chemical activation of slags, burden with certain ratios was prepared consisting of copper and molybdenum slags, as well as $\mathrm{NaNO}_{3}$ and $\mathrm{CaO}$.

The dependence of the burden phase and structural changes on the following weight ratios of copper (samples No. 1 and No. 2) and molybdenum (sample No. 3) slags-1:1, 3:1 and 4:1 is studied. The burdens were prepared according to the calculated amounts taking into consideration that the copper slag contains $35 \% \mathrm{Fe}$ and $17.5 \% \mathrm{Si}$, and the molybdenum slag- $41 \%, 53 \% \mathrm{Si}$. Those ratios of the slags are introduced in the table (see Table 1).

After the mechanochemical activation, the phase composition is studied on General Purpose X-ray Diffractometer (DRON-3) diffractometer operating with $\mathrm{Cu}-\mathrm{K} \alpha$-radiation. The $\mathrm{X}$-ray holography is carried out in continuous mode within the angle interval of $2 \theta=10^{\circ} \ldots 90^{\circ}$. The experiments are carried out with various ratios of both converter molybdenum and waste molybdenum slags to find out the advantage of those waste slags due to the mechanochemical activation (since these iron-containing slags are almost equivalent and in both of them the main minerals are fayalite and magnetite). To obtain comparable data, the experiments have been carried out under equal conditions.

\section{The Results of Mechanochemical Activation of the Burdens}

For the experiments of the first group, the mechanochemical activation of samples No. 1, No. 1.1 and No. 1.2 is carried out with the ratio 1:1 of converter $(20 \mathrm{~g})$ and molybdenum $(20 \mathrm{~g})$ slags. At that, sample No. 1 without added components, sample No. 1.1: in the presence of $2.5 \mathrm{~g} \mathrm{KNO}_{3}$; No. 1.2: $2.5 \mathrm{~g} \mathrm{NaNO}_{3}$ and $2.5 \mathrm{~g} \mathrm{CaO}$ (these conditions of experiments are repeated for all the ratios). The X-ray holograms of the investigated samples are introduced in Figure 1.

As it can be seen from the comparison of X-ray holograms, the phase composition has changed due to the result of 60-minute grinding. Compared with the initial slags, the reflections of magnetite have significantly increased and new phases have occurred which can be identified with $\mathrm{CaSiO}_{3}$ and $\mathrm{Na}_{2} \mathrm{SiO}_{3}$ reflexes.

The investigation of samples No. 2, No. 2.1 and No. 2.2 is carried out under the conditions of the same ratio of waste and molybdenum slags and the same composition of samples No. 1, No. 1.1 and No. 1.2. The comparison of the X-ray holograms of the investigated samples shows (Figure 2) that the results of the 60-minute mechanochemical activation have significantly changed, but the forms of reflections have changed more connected with strong amorphisation of the phases contained in the composition of the burden.

It can be seen more clearly in Figure 3, introducing the mirror image of Figure 2. In this case, the crystalline structure is practically lacking, therefore, the phase identification process becomes difficult.

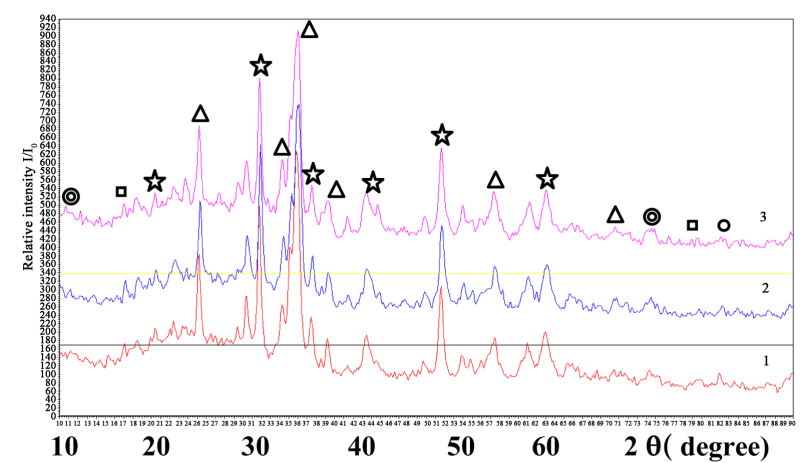

Figure 1. Comparison of X-ray holograms of the samples under the conditions of slag ratio 1:1 (where: $\mathrm{Fe}_{3} \mathrm{O}_{4}, \Delta-\mathrm{Fe}_{2} \mathrm{SiO}_{4}, \odot-\mathrm{SiO}_{2},--\mathrm{Na}_{2} \mathrm{SiO}_{3}, \circ-\mathrm{CaSiO}_{3}$ ).

Table 1. Slag ratios in the burden.

\begin{tabular}{|c|c|c|c|c|c|c|}
\hline \multirow[b]{2}{*}{ Used component } & \multicolumn{6}{|c|}{ Slag ratios in the burden } \\
\hline & $\begin{array}{c}\text { Con./mol } \\
1: 1\end{array}$ & $\begin{array}{c}\text { Was./mol. } \\
1: 1\end{array}$ & $\begin{array}{c}\text { Con./mol. } \\
\text { 3:1 }\end{array}$ & $\begin{array}{c}\text { Was./mol. } \\
\text { 3:1 }\end{array}$ & $\begin{array}{c}\text { Con./mol. } \\
4: 1\end{array}$ & $\begin{array}{c}\text { Wast./mol. } \\
4: 1\end{array}$ \\
\hline Without component & 1 & 2 & 3 & 4 & 5 & 6 \\
\hline Added $2.5 \mathrm{~g} \mathrm{KNO}_{3}$ & 1.1 & 2.1 & 3.1 & 4.1 & 5.1 & 6.1 \\
\hline Added $2.5 \mathrm{~g} \mathrm{KNO}_{3}$ and $2.5 \mathrm{~g} \mathrm{CaO}$ & 1.2 & 2.2 & 3.2 & 4.2 & 5.2 & 6.2 \\
\hline
\end{tabular}




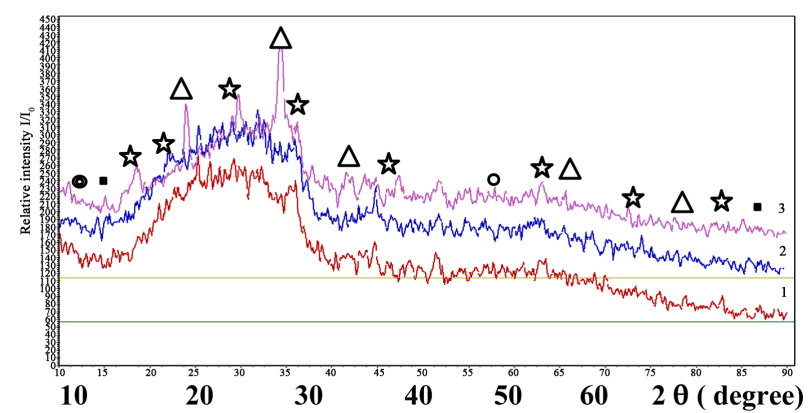

Figure 2. Comparison of X-ray holograms of the samples under the conditions of slag ratio 1:1 (where: $-\mathrm{Fe}_{3} \mathrm{O}_{4}, \Delta-\mathrm{Fe}_{2} \mathrm{SiO}_{4}, \odot-\mathrm{SiO}_{2},-\mathrm{Na}_{2} \mathrm{SiO}_{3}, \circ-\mathrm{CaSiO}_{3}$ ).

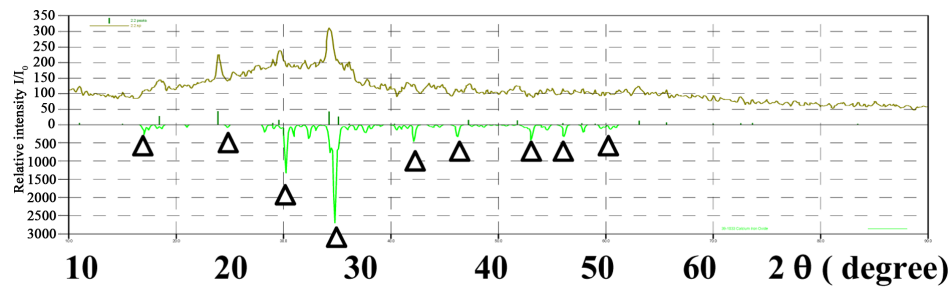

Figure 3. Mirror image of sample X-ray hologram (mirror image of the mineral $\left.\mathrm{Fe}_{2} \mathrm{SiO}_{4}\right)$.

Similar experiments are conducted for the converter $(30 \mathrm{~g})$ and molybdenum $(10 \mathrm{~g})$ slag ratio 3:1. The comparison of the X-ray holograms (Figure 4) shows that here as well, the 60-minute mechanical activation leads to a significant amorphisation of reflections, and to an increase in magnetite reflexes.

The conditions of experiments are the same for the ratio 3:1 of the waste and molybdenum slags undergone the mechanochemical activation. The comparison of the X-ray holograms (see Figure 5) shows that the 60minute mechanical activation leads to a significant change in the phase composition. In this case, as well, generation and significant amorphisation of new phases can be seen $\left(\mathrm{Ca}_{2} \mathrm{SiO}_{4}\right.$ and $\left.\mathrm{Na}_{2} \mathrm{SiO}_{3}\right)$ completely lacking crystalline lattice thus making the identification of reflexes difficult. However, in this case, the reflections of magnetite notably increase, while those of fayalite decrease.

The conditions of experiments are also the same for the ratio $4: 1$ of the converter $(40 \mathrm{~g})$ and molybdenum (10 g) slags subjected to the mechanochemical activation. The comparison of the X-ray holograms (see Figure 6) shows that the 60-minute mechanical activation leads to a significant change in the phase composition and amorphisation. In this case, it is connected with the small content of molybdenum slag leading to a significant decrease in the content of amorphous $\mathrm{SiO}_{2}$. It is an advantage, since, compared with the previous cases, the iron oxides do not link up with $\mathrm{SiO}_{2}$, artificially increasing the fayalite amount, but remain free and amorphous. The presence of $\mathrm{CaO}$ contributes to the occurrence of $\mathrm{Ca}_{2} \mathrm{SiO}_{4}$ and $\mathrm{Na}_{2} \mathrm{SiO}_{3}$ which remain in the slag. Here it is confirmed by the X-ray hologram-the generation of new phases $\left(\mathrm{Ca}_{2} \mathrm{SiO}_{4}\right.$ and $\left.\mathrm{Na}_{2} \mathrm{SiO}_{3}\right)$ and considerable amorphisation take place completely lacking crystalline lattice, thus making the identification of reflexes difficult. Thus in this case, $\mathrm{NaNO}_{3}$ and $\mathrm{CaO}$ play a positive role in the process. In case of waste $(40 \mathrm{~g})$ and molybdenum (10 g) slag ratio 4:1, the comparison of the X-ray holograms (see Figure 7) shows that here the 60-minute mechanical activation leads to an essential change in the phase composition and amorphisation. The widening of the existing reflections takes place bringing to essential decrease in the crystallization degree. These results are more efficient since a deeper amorphisation occurs on which only magnetite's reflections can be seen identical to those of iron oxides.

Thus, the comparison of the X-ray holograms shows that the best results are obtained in case of the waste and molybdenum slag ratio 4:1, when the method of mechanochemical activation is the most efficient one. Figures after mechanochemistry, when comparing the X-ray, shows that the X-ray diffraction patterns, especially at 60-minutes activation in the vibrating mill (see Figure 7), represent an amorphous halo, i.e. almost complete absence of the crystalline component in the samples, so that the phase identification is not possible.

Here are formed free amorphous iron and silicon oxides. When the ratio of $\mathrm{FeO}: \mathrm{SiO}_{2}=4: 1$, there are condi- 
V. H. Martirosyan, M. E. Sasuntsyan

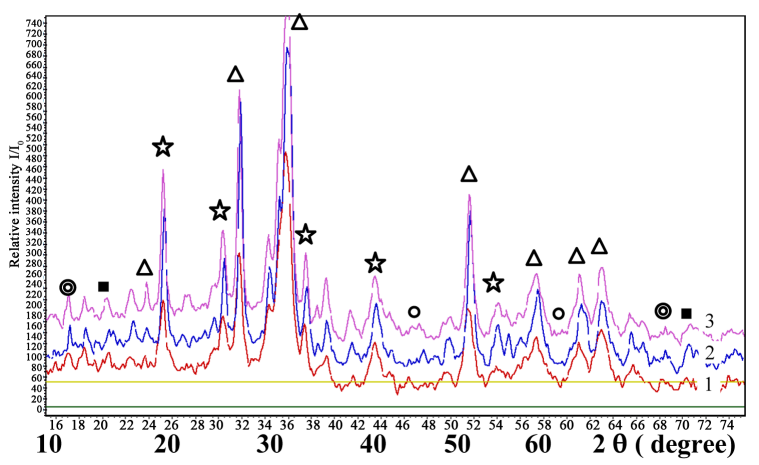

Figure 4. Comparison of X-ray holograms of the samples under the conditions of slag ratio 3:1 (where: $\downarrow-\mathrm{Fe}_{3} \mathrm{O}_{4}, \Delta-\mathrm{Fe}_{2} \mathrm{SiO}_{4}$, ๑ $-\mathrm{SiO}_{2},--\mathrm{Na}_{2} \mathrm{SiO}_{3}, \circ-\mathrm{CaSiO}_{3}$ ).

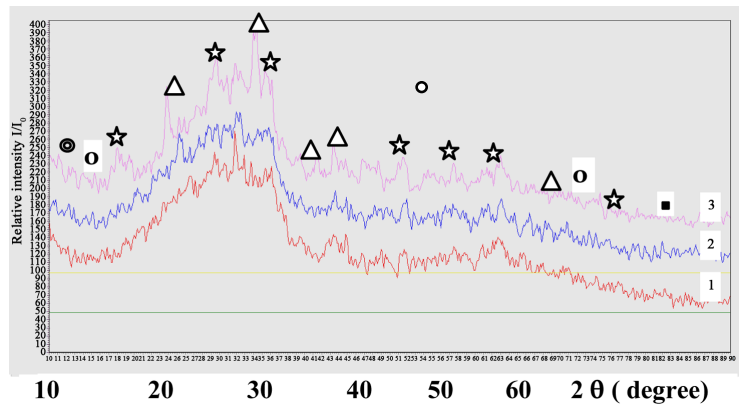

Figure 5. Comparison of X-ray holograms of the samples under the conditions of slag ratio 3:1 (where: $-\mathrm{Fe}_{3} \mathrm{O}_{4}, \Delta-\mathrm{Fe}_{2} \mathrm{SiO}_{4}, \odot-\mathrm{SiO}_{2},--\mathrm{Na}_{2} \mathrm{SiO}_{3}, \circ-\mathrm{CaSiO}_{3}$ ).

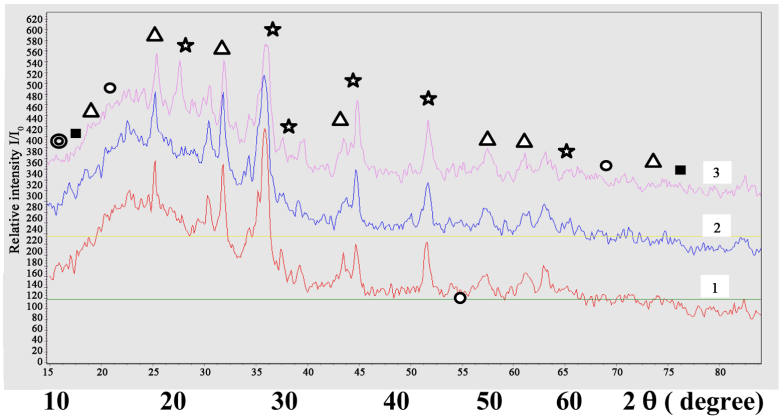

Figure 6. Comparison of X-ray holograms of the samples under the conditions of slag ratio 4:1. (where: $\bullet-\mathrm{Fe}_{3} \mathrm{O}_{4}, \Delta-\mathrm{Fe}_{2} \mathrm{SiO}_{4}, \odot-\mathrm{SiO}_{2}, \bullet-\mathrm{Na}_{2} \mathrm{SiO}_{3}$, $\bullet-\mathrm{CaSiO}_{3}$ ).

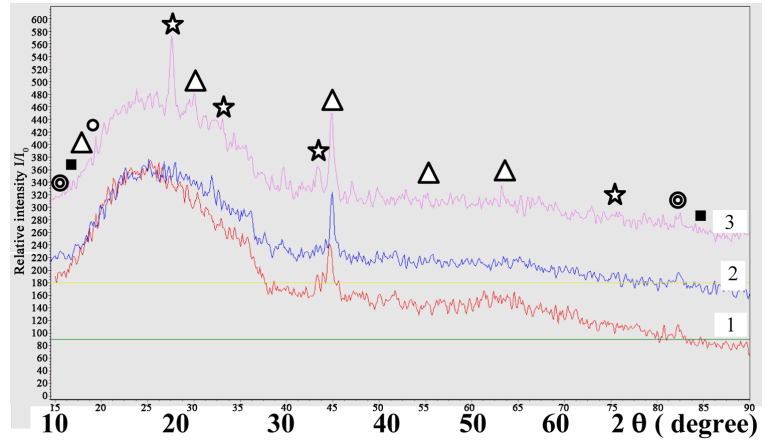

Figure 7. Comparison of X-ray holograms of the samples under the conditions of slag ratio 4:1 (where:- $-\mathrm{Fe}_{3} \mathrm{O}_{4}, \Delta-\mathrm{Fe}_{2} \mathrm{SiO}_{4}, \odot-\mathrm{SiO}_{2},--\mathrm{Na}_{2} \mathrm{SiO}_{3}$, $-\mathrm{CaSiO}_{3}$ ).

15 
tions for obtaining iron monosilicide. With an excess of $\mathrm{SiO}_{2}$, it is recovered up to the silicon. Other silicides $\left(\mathrm{FeSi}_{2}, \mathrm{Fe}_{2} \mathrm{Si}_{5}\right)$ are obtained as well. And on the contrary, an excess of $\mathrm{FeO}$ compared to $\mathrm{SiO}_{2}$, forms silicides with high iron content $\left(\mathrm{Fe}_{3} \mathrm{Si}_{2} \mathrm{Fe}_{2} \mathrm{Si}_{2}, \mathrm{Fe}_{5} \mathrm{Si}_{3}\right)$. The magnetic properties are manifested only by the iron monosilicide. Other silicides do not show magnetic properties.

In general, those transformations lead to reduction of activation energy of the reaction of the interacting substances and the chemical activity increases. It brings to the new course of reaction, with formation of new structures.

The morphological investigation of the burden particles' surface can lead to revelation of the structural change patterns and at the same time, the results of X-ray holograms can be confirmed. In the pictures below (see Figures 8(a)-(c)) the morphological studies of the burden activated in vibromill for 60 minutes and consisting of waste and molybdenum slags with ratio $4: 1$ at different enlargements are introduced. The studies have been carried out by the microroentgenospectral method through the element distribution map on the samples' surface.

As it can be seen in the figures (see Figure 8(a)), the increase of the mechanoactivated burden surface by 500 times can lead to covering the magnetite, iron $\left(\mathrm{FeO}, \mathrm{Fe}_{2} \mathrm{O}_{3}, \mathrm{Fe}_{3} \mathrm{O}_{4}\right)$, mixture oxides $\left(\mathrm{CaO}, \mathrm{MgO}, \mathrm{K}_{2} \mathrm{O}\right)$, and fayalite $\left(\mathrm{FeO}, \mathrm{SiO}_{2}\right)$ (the dark part) particles with the silicon dioxide (the light part). Here the borders are well outlined. The increase of the particle sizes by 3000 and 25,000 times leads to appearing the fusion within the inter-phase surface, which, in its turn brings to a distortion of the surface borders and amorphisation. Especially, at the enlargement of 25,000 times, some spongy masses can be seen (Figure 8(c)) covered by the colloidal particles of silicon dioxide. Here, one can clearly see the amorphous structure of the burden. However, everywhere, the general patterns are observed: the borders of different oxides (the dark part) with the silicon oxide (the light part).

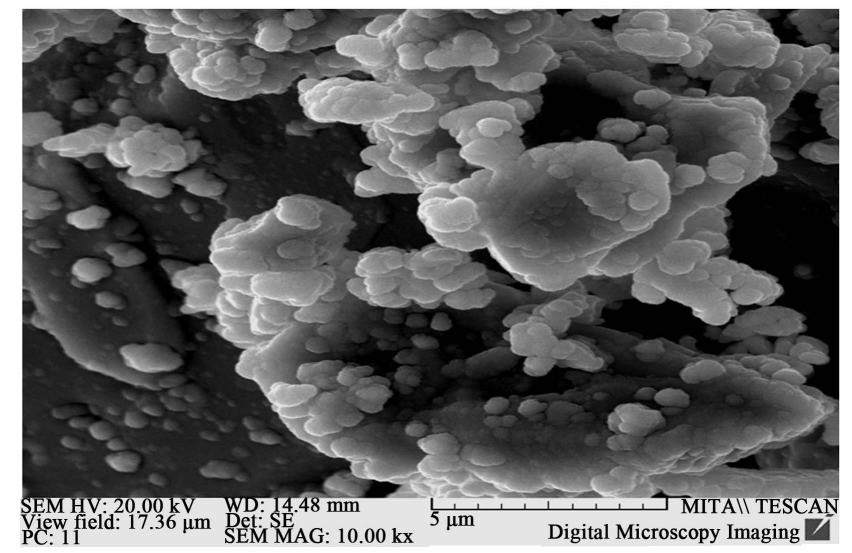

(a)

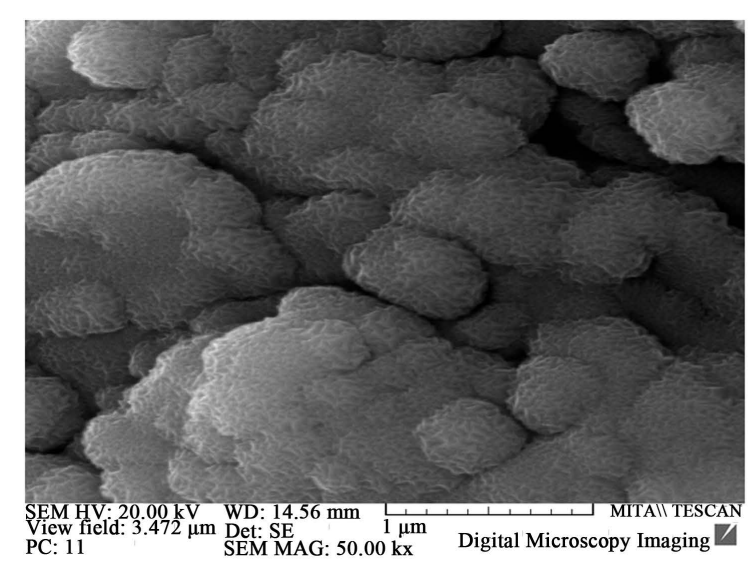

(a)

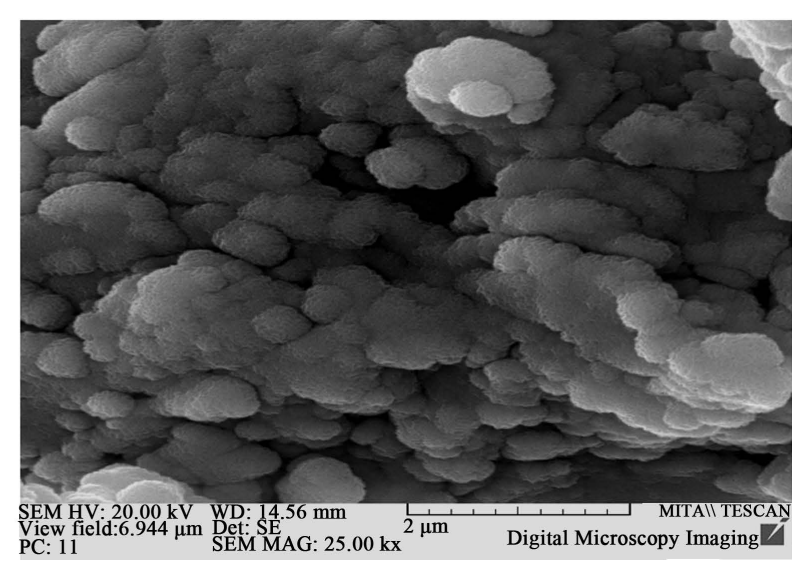

(b)

Figure 8. Morphology of the burden (a, b, c) activated in the vibromill for 60 minutes. (a) $\times 500$; (b) $\times 10,000$; (c) $\times 25,000$. 
At the same time, the morphological studies of the burden surface confirm that in case of mechanochemical activation of the burden, there are amorphous free iron and silicon oxides on the surface. Thus, the mechanochemical activation favors the increase in the burden's reaction activity.

\section{Conclusions}

The behaviour of the machnoactivated burden (initial material) under the condition of 60-minute grinding in the vibromill is studied. It is shown that due to grinding, fayalite and magnetite, as the main components of the burden, undergo deep chemical transformations as a result of which the minerals decompose generating amorphous iron $\left(\mathrm{FeO}, \mathrm{Fe}_{2} \mathrm{O}_{3}, \mathrm{Fe}_{3} \mathrm{O}_{4}\right)$ and silicon oxides. The activated amorphous oxides are reactive and can serve as raw material for obtaining iron-silicon additives by the method of self-propagating high-temperature synthesis. Meanwhile, during the process of obtaining ferrosilicium from the preliminary mechanoactivated burden by the SHS method, due to increasing the contact surface and particle amorphisation, the synthesis will proceed at small activation powers and low temperatures. The presence of small particles will become a basis for simultaneous generation of numerous crystallization centers which will grow at low temperatures before the liquid phase occurrence. It will affect the structure and phase-formation process of the obtained alloy. A striped microheterogeneous SHS process will take place by a different route of chemical reaction, since during the fine grinding, the reaction will proceed with the pure iron and silicon oxides completely free from mixtures. The generation of new phase crystallization centers will be accompanied by obtaining a new nano-structured alloy.

Thus, the mechanochemical activation by the method of fine grinding is an efficient method for increasing the reaction capacities of difficulty to process metallurgical slags which will also favor the cause of alloys with new structures.

Further experimental studies have confirmed the reliability of these findings [2].

It is an important circumstance which should be taken into account in the process of solving technological problems concerning the waste slags obtained while processing ferrous and non-ferrous metals by pyrometallurgical method [10] [11].

The investigation was carried out due to financial support of the State Science Committee of RA Ministry of Science and Education in the framework of the Armenian-Belorussian joint scientific project No. 13RB049.

\section{References}

[1] Belyaev, E.Y., Lomovsky, O.I. and Golubkov, G.V. (1998) Way of Receiving Thermoelectric Material on the Basis $\beta$-FeSi ${ }_{2}$. Patent RF No. 96116968/25.

[2] Martirosyan, V.A., Sasuntsyan, M.E., Chitanyan, A.O., Nikoghosyan, A.S. and Talako, T.L. (2012) High-Temperature Synthesis of Ferrosilicon from Iron and Silicon-Containing Slag Production. Proceeding of SEUA, Series: Metallurgy, Material Science, Mining Engineering, 15, 19-27.

[3] Durrer, R. and Folkert, G. (1976) Metallurgy of Ferroalloys. M. Metallurgy, 47 p.

[4] Revenko, A.G. (1994) X-Ray Spectral Fluorescence Analysis of Natural Materials Novosibirsk. Science, 264 p.

[5] Mazalov, L.N. (1982) X-Ray Spectral and Chemical Relation. Novosibirsk, Nauka, 111 p.

[6] Pichugin, V.F., Yanovskiy, V.P., Morosova, N.S. and Yermolovich, I.M. (2010) Modification of Materials with Particle Beams and Plasma Flows. Proceedings of the 10th International Conference on Modification of Materials with Particle Beams and Plasma Flows, Tomsk, 27 April 2010, 672-675.

[7] Philipova, N.A. (1975) Phase Analysis of Ores and Products of Their Processing. M. Chemistry, 280 p.

[8] Avvakumov, E.G., Boldirev, V.V. and Kosobudski, I.D. (1972) Mechanical Activation of Solid-Phase Reactions. The Interaction of Pyrite with Iron. Proceedings of AS USSR, Series: Chemical Sciences, 4, 45-50.

[9] Boldirev, V.V. (2006) Mechanical Chemistry and Mechanical Activation of Solid Substances. Achievements of Chemistry, 75, 203-216.

[10] Talako, T.L., Grigorieva, T.F., Letsko, A.I., Barinova, A.P., Vitiaz, P.A. and Lyakhov, N.Z. (2009) Mechanical Activated SHS of FeAl-Based Nanocomposite Powders. International Journal of Self-Propagating High-Temperature Synthesis, 18, 125-132.

[11] Letsko, A.K., Talako, T.H., Ilyushchenko, A.F., Grigorieva, T.F. and Lyakhov, N.Z. (2009) Mechanical Activation of the Charge for the SHS Iron Aluminide. Chemistry for Sustainable Development, 27, 621-628. 